\title{
Corrigendum
}

\section{Using the Mellor-Yamada mixing scheme in seasonally ice-covered seas-Corrigendum to: Parameterization of vertical mixing in the Weddell Sea [Ocean Modelling 6 (2004) 83-100]}

\author{
Ralph Timmermann *, Martin Losch \\ Alfred Wegener Institute for Polar and Marine Research, Postfach 120161, 27515 Bremerhaven, Germany
}

Available online 14 December 2004

\begin{abstract}
A coding error in the s-Coordinate Primitive Equation Model (SPEM) has led to misleading statements about the behaviour of the Mellor-Yamada level 2 parameterization of vertical mixing. It has been claimed that the scheme removes static instability only very slowly and preserves statically unstable stratifications for an unrealistic long time. This note corrects this statement by demonstrating that the Mellor-Yamada mixing scheme, if implemented correctly, tends to overestimate rather than underestimate vertical mixing in seasonally ice-covered seas. Similar to other mixing schemes with the same behaviour, this leads to spurious open ocean deep convection, an unrealistic homogenization of the water column, and a significant reduction of sea ice volume.
\end{abstract}

(C) 2004 Elsevier Ltd. All rights reserved.

Keywords: Coupled sea ice-ocean model; Vertical mixing; Parameterization of convection Regional terms: Southern Ocean; Weddell Sea

DOI of original article: 10.1016/S1463-5003(02)00061-6

* Corresponding author. Tel.: +49 4714831 1796; fax: +49 47148311797.

E-mail address: rtimmerm@awi-bremerhaven.de (R. Timmermann). 


\section{Introduction}

In a recent issue of Ocean Modelling, Timmermann and Beckmann (2004), refered to as TB04 hereafter, presented a comparison of vertical mixing schemes for the seasonally ice-covered Southern Ocean. The major results of their study, namely the importance of wind-induced mixing during the summer period and the good performance of a modified Pakanowski-Philander scheme (among others), are still valid. However, a coding error in the relevant routine of the S-coordinate Primitive Equation Model SPEM (Haidvogel et al., 1991; Version 5.1) led the authors to misleading statements about the behaviour of the Mellor-Yamada mixing scheme. A sign error caused the scheme to generate turbulent kinetic energy only in case of a statically stable stratification, but not in case of static instabilities. Clearly this is not realistic and was not intended by Mellor and Yamada (1982).

Having realized this, we repeated the experiments conducted with the Mellor-Yamada scheme. This note presents the results using a correct implementation of the scheme. As in TB04, we use the BRIOS-2 coupled sea ice-ocean model (Timmermann et al., 2002), integrated over two passes of the 1985-1993 ECMWF reanalysis dataset. Following the original paper, we compare simulation results to climatological fields from the Hydrographic Atlas of the Southern Ocean (Olbers et al., 1992), and to results from a reference simulation which employs a Richardson-number dependent mixing scheme (modified after Pacanowski and Philander, 1981) complemented with a diagnostic computation of the Monin-Obukhov length to improve the representation of wind-induced mixing (cf. TB04 for details).

\section{Results}

A comparison (Fig. 1) of a simulated quasi-meridional temperature section through the Weddell Sea to data from the Hydrographic Atlas of the Southern Ocean (Olbers et al., 1992) indicates that the level 2 mixing scheme of Mellor and Yamada (1982), if implemented correctly, overestimates the effect of vertical mixing in the seasonally ice-covered Southern Ocean. From the third year of integration onwards, the core of the warm deep water (WDW) is subsequently eroded. After 10 years of integration, major parts of the Weddell Sea feature a rather homogeneous water column with a potential temperature between -0.4 and $0{ }^{\circ} \mathrm{C}$. Deep convection at this stage establishes a direct exchange between the surface and the bottom ocean (Fig. 1, right). This process is still very active at the end of the experiment and clearly not realistic.

Despite the large vertical heat flux associated with the deep convection in this experiment, largescale open ocean polynyas do not occur. However, simulated winter sea-ice thickness in the Maud Rise area is only $0.15 \mathrm{~m}$, compared to values of $0.5-0.8 \mathrm{~m}$ that are typical in the reference experiment and the observations of Harms et al. (2001).

Another prominent result in TB04 was the very slow spreading of an artificial passive tracer that has been released in the surface layer above the Weddell Sea continental shelf (Fig. 4 in TB04, in which the 'PP' flag in the left panel should have read 'MY'). Not surprisingly, this result can be explained by the incorrect computation of turbulent kinetic energy. After correcting the error in the MY experiment, the tracer spreads in a similar manner as in the reference simulation (Fig. 2). 

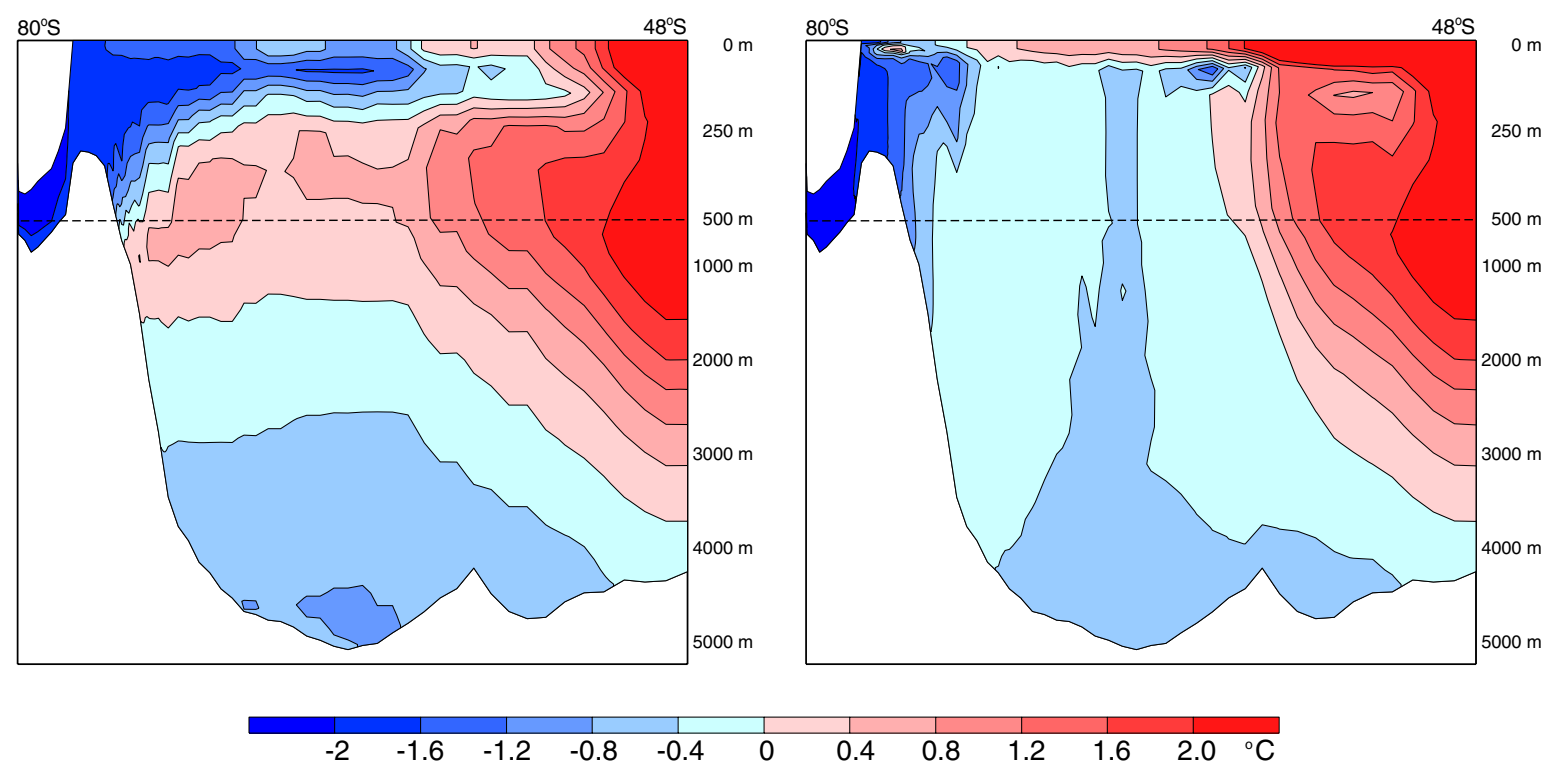

Fig. 1. Summer temperature section through the Weddell Sea according to the Hydrographic Atlas of the Southern Ocean (Olbers et al., 1992) (left) and in an experiment with the corrected Mellor-Yamada turbulence closure scheme after 18 years of integration (right). The upper $500 \mathrm{~m}$ of the section have been stretched.

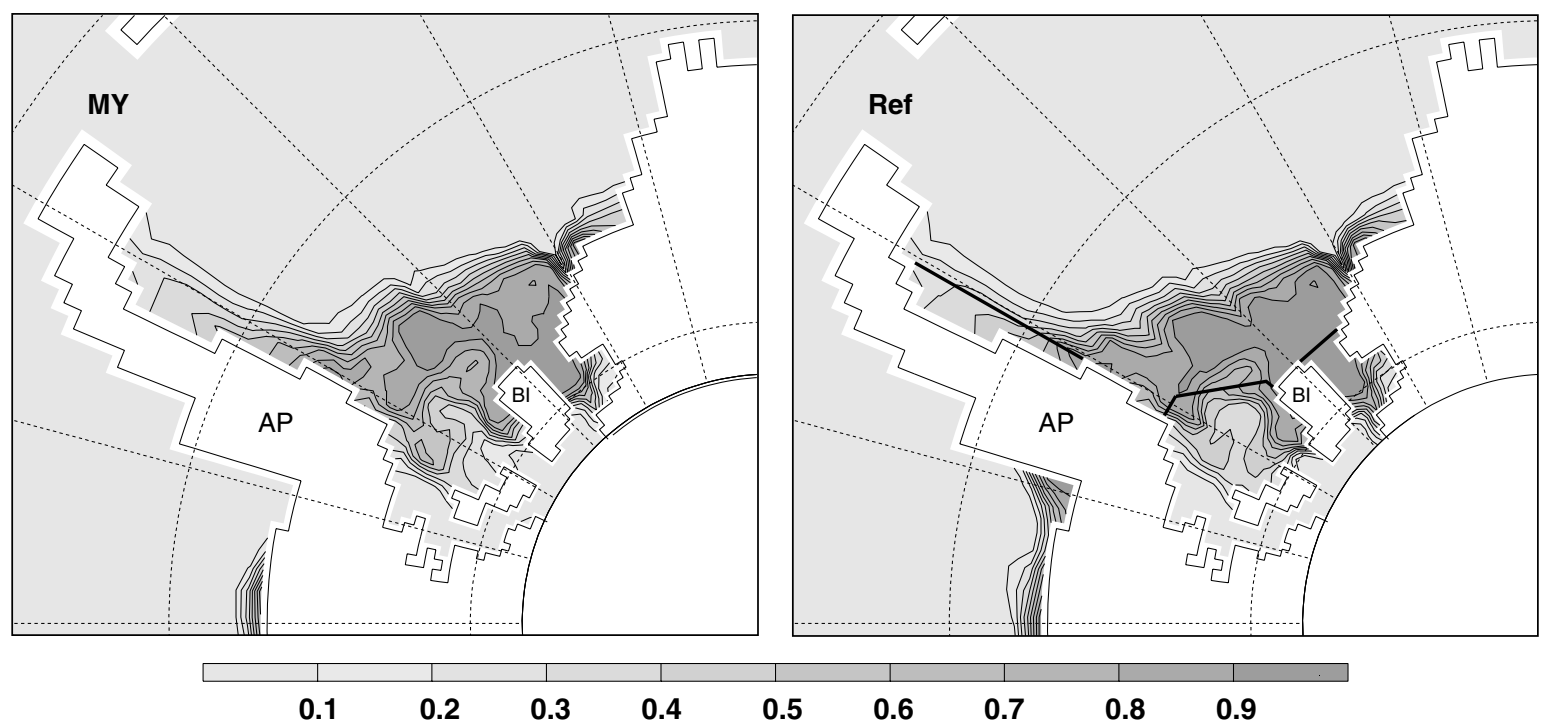

Fig. 2. Bottom-layer concentrations of an artificial tracer homogeneously released at the Weddell Sea surface in the experiment using the (corrected) Mellor-Yamada turbulent closure scheme (left) and in the reference simulation of TB04 (right), after three years of integration. BI: Berkner Island; AP: Antarctic Peninsula.

In the experiments of TB04, simulations with the MY mixing scheme featured the smallest meridional overturning of all experiments ( $24 \mathrm{~Sv}$ total overturning compared to $26 \mathrm{~Sv}$ in the 
reference simulations and up to $34 \mathrm{~Sv}$ in the sensitivity experiments). Now, with the numerics corrected, total overturning in the MY experiment exceeds $33 \mathrm{~Sv}$ in the nine-year mean. This value is consistent with the vigorous deep convection in this particular experiment.

\section{Summary}

After correcting the implementation of the Mellor and Yamada (1982) parameterization of vertical mixing in the BRIOS-2 coupled ice-ocean model, the statement that this scheme removes static instability only very slowly (Timmermann and Beckmann, 2004) has to be withdrawn. Simulations with the correct numerics yield results very close to other traditional mixing schemes: Deep convection in the seasonally ice-covered (Southern) ocean is overestimated significantly, which results in an unrealistic homogenization of the water column and a spurious thinning of sea ice. However, the main conclusions of TB04, namely the importance of wind-induced mixing during summer and the superior performance of two vertical mixing schemes that take into account the Monin-Obukhov length (as a function of $\mathrm{u}^{* 3}$ ) remain valid.

\section{Acknowledgements}

We would like to thank Kate Hedstrom for her rapid response and Scott Durski for a short but fruitful discussion.

\section{References}

Haidvogel, D.B., Wilkin, J.L., Young, R.E., 1991. A semi-spectral primitive equation ocean circulation model using vertical sigma and orthogonal curvilinear horizontal coordinates. Journal of Computational Physics 94, $151-185$.

Mellor, G.L., Yamada, T., 1982. Development of a turbulence closure model for geophysical fluid problems. Reviews of Geophysics and Space Physics 20 (4), 851-875.

Olbers, D., Gouretski, V., Seiss, G., Schröter, J., 1992. Hydrographic Atlas of the Southern Ocean. Alfred-WegenerInstitut für Polar- und Meeresforschung, Bremerhaven, $99 \mathrm{pp}$.

Pacanowski, R.C., Philander, S.G.H., 1981. Parameterization of vertical mixing in numerical models of the tropical oceans. Journal of Physical Oceanography 11, 1443-1451.

Timmermann, R., Beckmann, A., Hellmer, H.H., 2002. Simulation of ice-ocean dynamics in the Weddell Sea. Part I: Model configuration and validation. Journal of Geophysical Research 107 (C3), 10.1029/2000JC000741.

Timmermann, R., Beckmann, A., 2004. Parameterization of vertical mixing in the Weddell Sea. Ocean Modelling 6 (1), $83-100$. 